\title{
Toekomstbestendige zorg: van visie naar actie!
}

\author{
Thomas Plochg · Jolanda Keijsers · Lode Wigersma
}

Published online: 15 March 2017

(C) Bohn Stafleu van Loghum 2017

Samenvatting Het huidige zorg- en verdienmodel is hoofdzakelijk gebaseerd op het leveren van curatieve zorg. Dat model is dringend aan vernieuwing toe. Want de kosten voor zorg blijven maar stijgen en beslaan momenteel al meer dan een kwart van de overheidsbegroting. Dit zorgstelsel kan en zal de samenleving zo niet handhaven. Want het is niet in staat de grote gezondheidsproblemen en -bedreigingen, liefst in een vroeg stadium, het hoofd te bieden. De financiële problemen van ziekenhuizen zijn wat dat betreft een eerste signaal. Er worden nieuwe, concurrerende modellen ontwikkeld die positieve gezondheid en preventie als vertrekpunt nemen. Artsen moeten daarin meedoen om als beroepsgroep geloofwaardig en effectief te blijven. Onlangs zijn in dit kader verschillende adviezen en visies neergelegd, en gerelateerd daaraan, aangrijpingspunten voor verandering. Dit zowel vanuit de hoek van de overheid, de publieke gezondheidssector, als ook door de artsen zelf. Wat behelzen deze adviezen en visies, en hoe verhouden ze zich tot elkaar?

Dr. T. Plochg $(\varangle)$

NPHF Federatie voor Gezondheid, Utrecht, Nederland t.plochg@nphf.nl

Dr. T. Plochg

Afdeling Sociale Geneeskunde AMC/UvA, Amsterdam, Nederland

Dr. J. Keijsers

TNO, Leiden, Nederland

Dr. L. Wigersma

NVAG, vereniging van sociaal geneeskundigen werkzaam in beleid, management en onderzoek, Utrecht, Nederland

\section{Belang van voorzorg}

Door de grote nadruk op curatieve zorg is de gezondheidszorg in ons land en andere westerse landen steeds minder toegespitst op de ziekten van vandaag en morgen. De meest voorkomende gezondheidsproblematiek is tegenwoordig meervoudig en chronisch van aard. Volgens het RIVM kampt ongeveer $11 \%$ van de Nederlanders (1,9 miljoen mensen) met twee of meer ziekten (multimorbiditeit), vaak in combinatie met problemen op andere leefgebieden [1].

De versnipperde organisatie van de curatieve zorg in een groot aantal (sub)specialismen heeft hier geen adequaat antwoord op. Een zorgstelsel dat een tiental specialisten rondom één patiënt organiseert, is eenvoudigweg niet meer te bemensen en te betalen. En is bovendien ineffectief omdat daarbij niet 'de hele mens' wordt beschouwd maar een verzameling 'onderdelen' [2]. De OESO rapporteerde begin dit jaar dat er nog nooit zoveel artsen en verpleegkundigen waren [3]. Tevens is er steeds meer onderzoeksbewijs dat zo'n twee derde van de zorguitgaven wordt besteed aan mensen met multimorbiditeit [4]. Mensen worden niet gezonder door al die specialistische deeloplossingen bij elkaar op te tellen. De meeste van de grote gezondheidsproblemen interacteren en kennen gemeenschappelijke oorzaken in een ongezonde leefstijl en slechte leefomgeving [5].

Ze vragen dan ook om een verschuiving in benadering naar de voorkant van problemen, ofwel van nazorg naar voorzorg [6]. ${ }^{1}$ Concreet betekent dat een intrinsieke oriëntatie op zowel het voorkómen van, als

\footnotetext{
${ }^{1}$ De slogan 'van nazorg naar voorzorg' is gemunt door de NPHF Federatie voor Gezondheid. Het is een van de duidingen van de dynamiek die nu in de gezondheidszorg steeds zichtbaarder wordt. Andere voorbeelden zijn 'van Ziekte en Zorg naar Gezondheid en Gedrag (van ZZ naar GG)', 'kantelen' en 'transformatie'.
} 
het anticiperen op gezondheidsproblemen, zodat die in een vroeg stadium kunnen worden gesmoord dan wel verzacht.

In het veld zijn initiatieven genomen waarin gewone zorgverleners, welzijnswerkers en burgers pionieren. Denk aan Vitaal Vechtdal, Utrecht Overvecht Gezond, Blauwe zorg in Limburg, de Veenkoloniën. Ook de 280 pledges in het Alles is Gezondheid-programma illustreren dit [7]. Tegelijkertijd wordt de ziekenhuiszorg geconcentreerd en gecentraliseerd, vindt er een verschuiving van de tweede naar de eerste lijn plaats en worden bruggen geslagen naar het sociale domein.

Deze beweging vindt deels haar oorsprong in het recente overheidsbeleid. De Rijksoverheid heeft in 2015 de jeugdzorg en de Wmo-zorg aan de gemeenten overgedaan, zij het met een forse korting op het budget. De aanleiding is in de eerste plaats financieel, maar ook de gedachte dat de overheid op gemeentelijk niveau de hulp beter kan organiseren en meer maatwerk kan leveren speelde en speelt een rol. Gemeenten beseffen steeds beter dat juist in de gemeentelijke context kan worden gezocht naar nieuwe, proactieve en integrale vormen van zorg, welzijn en preventie.

\section{Visies en adviezen}

\section{Advies van de Commissie Innovatie Zorgberoepen \& Opleidingen}

Minister Schippers preludeerde er al op in het interview in Medisch Contact [8] en het nieuwe kabinet heeft de twee adviezen van de Commissie Innovatie Zorgberoepen \& Opleidingen op het bureau liggen $[9,10]$. Beide adviezen agenderen zowel politiek als beleidsmatig de adequate toerusting van toekomstige generaties professionals, inclusief artsen.

In het eerste advies 'Naar nieuwe zorg en zorgberoepen, de contouren' zijn drie mogelijke uitgangspunten gedefinieerd: 1) de veranderende zorgvraag: wat is er nodig in 2030 ?, 2) functioneren: niet de ziekte als vertrekpunt maar het functioneren, en 3) een nieuw concept van gezondheid: veerkracht en eigen regie staan centraal [9].

In het tweede advies 'Anders kijken, anders leren, anders doen. Grensoverschrijdend leren en opleiden in zorg en welzijn in het digitale tijdperk' worden deze uitgangspunten doorvertaald naar de zorgopleidingen. Volgens de commissie is het essentieel dat er samenhang komt tussen vakbekwaamheid, samenwerkend vermogen en lerend vermogen. Een achttal hoofdlijnen wordt daarvoor aangereikt, die in zorgopleidingen zouden moeten worden ingebouwd (zie het kader) [10].

Het afschaffen van de medisch-specialistische beroepen is bij de voorgestelde verandering niet aan de orde. Wel ligt het in de lijn der verwachting dat de capaciteit van die beroepen de komende jaren wordt ingeperkt en geconcentreerd, ten faveure van de op- komende meer op voorzorg georiënteerde beroepsgroepen en bedrijven. Overigens is deze verschuiving, afgemeten aan het aantal fusies en (dreigende) faillissementen in de ziekenhuiszorg, reeds ingezet. Het gaat gepaard met een groeiende overcapaciteit aan zorgspecialisten.

\section{Professionele competenties}

Vakbekwaamheid vormt de basis van het professionele handelen. Het is gericht op het bevorderen en zo nodig herstellen van gezondheid met als focus het functioneren, de veerkracht en eigen regie van burgers. Functioneren, veerkracht en eigen regie zijn het perspectief in zorg- en welzijnsopleidingen, van mbo, hbo en wo tot en met postinitieel onderwijs en bij- en nascholing. Het uitgangspunt hiervoor is een biopsychosociaal model. Hierdoor worden onder meer zorg en welzijn met elkaar verbonden.

Samenwerkend vermogen ontwikkelt zich in de praktijk en de opleidingen. Toekomstige professionals maken kennis met de praktijk waarin ze samen leren en werken. Dat gebeurt al vanaf het begin van de opleiding door de praktijk in het onderwijs en onderwijs in de praktijk te halen. Dat vindt ook plaats door het ontwikkelen van consistente en op elkaar aansluitende leertrajecten in een continuüm, die uitgaan van kenmerkende praktijksituaties. Gemeenschappelijke kaders in een continuüm van mbo, hbo, wo, postinitieel onderwijs en bij- en nascholing leiden tot opleidingen met een bredere en sterkere kerninhoud en differentiatie in uitstroomprofielen ( $t$-shape). Een sterk accent komt te liggen op postinitieel onderwijs en bijen nascholing door de snelle veranderingen en de noodzaak om een leven lang vakbekwaam te blijven.

Het lerend vermogen van professionals is van essentieel belang. Kennis veroudert steeds sneller en permanent samen leren in teams, organisaties en netwerken draagt bij aan een betere aansluiting bij de veranderende hulp- en zorgvragen. Dit geldt in het bijzonder voor het leven, leren en werken met technologie, die zich spectaculair ontwikkelt. Permanente kennisdeling door de verbinding tussen onderzoek, onderwijs, praktijk en beleid is noodzakelijk om de kennis en bekwaamheden te ontwikkelen die vernieuwingen stimuleren en versnellen.

Persoonlijke ontwikkeling en het permanent delen van kennis kunnen alleen plaatsvinden in een omgeving die het leren met en van elkaar op de werkplek en in netwerken stimuleert en faciliteert. Dat vraagt om nieuwe vormen van leiderschap en toezicht, een transparant verantwoordingsproces en goede feedback. 
Hoofdlijnen in zorgopleidingen (Vervolg kader)

In het advies worden acht samenhangende hoofdlijnen genoemd die in zorgopleidingen centraal moeten staan:

1. functioneren, veerkracht en eigen regie van burgers;

2. burgers ontwikkelen van jongs af aan leer- en gezondheidsvaardigheden;

3. functioneren, veerkracht en eigen regie als rode draad door leertrajecten;

4. de praktijk in het onderwijs en onderwijs in de praktijk;

5. consistente en op elkaar aansluitende leertrajecten in een continuüm;

6. permanent leren in teams, organisaties en netwerken;

7. leven, leren en werken met technologie;

8. onderzoek, onderwijs, praktijk en beleid verbinden.

(Bron: Commissie Innovatie Zorgberoepen \& Opleidingen, 2016)

\section{Actieagenda Beroepen \& Opleidingen}

Complementair aan de voorgenoemde adviezen heeft de NPHF Federatie voor Gezondheid eind 2015 een interdisciplinaire actieagenda Beroepen \& Opleidingen opgesteld [11]. Daarin worden zes richtinggevende vaardigheidsgebieden benoemd voor de toekomstige zorgprofessionals (zie tab. 1). De toegevoegde waarde van de actieagenda betreft niet zozeer het benoemen van deze vaardigheidsgebieden, als wel de visie op het veranderproces die daaraan gekoppeld wordt.

De vaardigheidsgebieden worden niet verabsoluteerd, maar als een wenkend perspectief neergezet. De beroepsgroepen die in staat zijn zich langs de zes vaardigheidsgebieden te ontwikkelen zullen op termijn beter toegerust zijn, en zichzelf naar de toekomst toe maatschappelijk legitimeren.

\section{Medisch Specialist 2025}

Meedoen en meeveranderen lijkt dus het devies. De beroepsgroep staat daarbij voor een forse opgave: het in de basis veranderen van de organisatie van de beroepsgroep. Als artsen zich blijvend organiseren in acht separaat opererende beroepsverenigingen en 47 verschillende wetenschappelijke verenigingen, zal het vrijwel onmogelijk blijken om toekomstige artsen dusdanig toe te rusten dat ze een antwoord weten te geven op de behoeften die de patiënt en de samenleving hebben.

In het visiedocument 'Medisch Specialist 2025' van de Federatie Medisch Specialisten worden vier ont- wikkelingen geschetst waarbij moet worden aangesloten [12]:

- de unieke patiënt en de moderne specialist;

- de richting netwerkgeneeskunde;

- betrokken bij gezondheid en gedrag;

- voorop in vernieuwing.

In de uitwerking van deze ontwikkelingen wordt een medisch specialist geschetst die zich opstelt als coach, die multidisciplinair samenwerkt en de patiënt centraal stelt, bij wie het samen met de patiënt beslissen de dagelijkse praktijk kenmerkt, in wiens werk het contact via moderne technologie geïntegreerd is en die het concept van Positieve Gezondheid als uitgangspunt neemt (gezondheid als het vermogen zich aan te passen en een eigen regie te voeren, in het licht van de fysieke, emotionele en sociale uitdagingen van het leven). Tevens wordt gesteld dat dit om een wijziging in de opleidingen vraagt. Expliciet wordt in dat kader gesteld dat de behoefte aan breder opgeleide medisch specialisten zal toenemen door de toename van multimorbiditeit en chronische ziekten.

\section{Het Raamplan Artsenopleiding 2019 als lakmoesproef}

Een goede mogelijkheid om met de diverse adviezen concreet aan de slag te gaan, vormt het raamplan Artsenopleiding 2019 dat de komende periode wordt opgesteld. Het eerste dat moet gebeuren is het 'doorlichten' van de opleidingen van de basisarts en de verschillende medische specialismen op de volgende competentiegebieden:

- integrale zorg aan meervoudig chronisch zieken;

- voorkómen van ziekte, gebrek en de verergering van bestaande klachten en ziekten;

- prioriteit geven aan het functioneren en het 'meedoen' van de patiënt in de samenleving;

- helpen bevorderen van gezond leven en een gezonde omgeving;

- uitgaan van de wensen, verwachtingen en mogelijkheden van patiënten ten aanzien van hun leven, hun zorg en hun functioneren;

- aangaan van interdisciplinaire, structurele samenwerking in teams van professionals die daartoe overeenkomsten sluiten met burgers en patiënten, in plaats van zelf te bepalen wat er moet gebeuren.

Als dergelijke competenties op dit moment geen of onvoldoende onderdeel van opleidingseisen en beroepsprofielen uitmaken, dan is aanpassing van de beroepsprofielen en opleidingseisen een eerste vereiste.

Dat begint vanzelfsprekend in de basisartsopleiding, omdat daar het fundament wordt gelegd van een leven lang functioneren als arts. In de specialistenopleidingen zullen aanpassingen van het competentieprofiel uiteraard maatwerk zijn, dat wil zeggen met inachtneming van de kenmerken en hoofdtaken 
Tabel 1 Vaardigheidsgebieden toekomstige zorgprofessionals.

\begin{tabular}{|c|c|}
\hline vaardigheidsgebied & omschrijving \\
\hline $\begin{array}{l}\text { 1. Van behandelen van ziekten en } \\
\text { bestrijden van symptomen naar duur- } \\
\text { zaam stimuleren van gezondheid en } \\
\text { welbevinden }\end{array}$ & $\begin{array}{l}\text { Professionals zijn in staat om het dynamische concept van positieve gezondheid als leidmotief te nemen voor hun } \\
\text { denken en handelen. Ze verkrijgen inzicht in de veerkracht van mensen, hoe verschillende factoren daarop van in- } \\
\text { vloed zijn, hoe je die veerkracht kan vergroten door mensen te ondersteunen bij het ontwikkelen van hun gezond- } \\
\text { heidsvaardigheden en hoe zij hun bijdrage daaraan kunnen optimaliseren. }\end{array}$ \\
\hline $\begin{array}{l}\text { 2. Van ziekte centraal naar de cliënt } \\
\text { centraal }\end{array}$ & $\begin{array}{l}\text { Professionals zijn in staat om zodanig contact te maken met de cliënt dat ze diens unieke situatie kennen en begrij- } \\
\text { pen. Door een (levens)brede benadering te hanteren, leren ze te kijken naar de vraag achter de vraag, kunnen ze de } \\
\text { kwaliteit van leven vooropstellen en cliënten de regie over het eigen leven zo lang mogelijk laten behouden. }\end{array}$ \\
\hline $\begin{array}{l}\text { 3. Van individugericht naar het individu } \\
\text { in zijn omgeving en met zijn omgeving }\end{array}$ & $\begin{array}{l}\text { Professionals zijn in staat om de cliënt (of groepen van cliënten) in zijn brede context te beschouwen en daarop te } \\
\text { interveniëren. Gezond zijn en blijven doe je niet alleen. Elk mens functioneert in een omgeving. Hij woont in een wijk, } \\
\text { gaat om met andere mensen, wordt opgevoed met bepaalde normen en waarden, ondervindt steun en zorg van zijn } \\
\text { partner, vrienden en buren, via werk of op een andere manier in de samenleving. Veel mensen kunnen, mede door de } \\
\text { aanwezige steunsystemen en sociale netwerken in hun omgeving, blijven functioneren en thuis blijven wonen. }\end{array}$ \\
\hline $\begin{array}{l}\text { 4. Van probleemgericht naar benutten } \\
\text { van kansen en mogelijkheden }\end{array}$ & $\begin{array}{l}\text { Professionals zijn gericht op het benutten van kansen en mogelijkheden. De energie van cliënten zit veelal bij wat } \\
\text { goed gaat en niet bij wat fout gaat. Om een gedragsverandering te realiseren bij mensen is het de kunst om van dat } \\
\text { gegeven gebruik te maken. Op die manier sluit de professional aan bij de ambitie, interesse en mogelijkheden van } \\
\text { cliënten en helpt hij cliënten het vertrouwen in eigen kunnen te behouden of terug te vinden. }\end{array}$ \\
\hline $\begin{array}{l}\text { 5. Van solistisch werken naar interdis- } \\
\text { ciplinair samenwerken }\end{array}$ & $\begin{array}{l}\text { Professionals zijn naar buiten gericht, willen daadwerkelijk samenwerken en weten van elkaar hoe ze ieders exper- } \\
\text { tise, rol en verantwoordelijkheden optimaal kunnen inzetten om cliënten te ondersteunen, zodat deze gezond en vitaal } \\
\text { blijven participeren. }\end{array}$ \\
\hline 6. Van analoog naar digitaal werken & $\begin{array}{l}\text { Professionals weten wat hun toegevoegde waarde is in het digitale tijdperk. Ze zijn in staat om burgers en patiënten } \\
\text { te ondersteunen en helpen bij het gebruik van e-health om zorgkeuzen te maken en gezond en vitaal te blijven. }\end{array}$ \\
\hline & \\
\hline
\end{tabular}

van het specialisme en de aard van de zorgvraag. Het behoeft geen betoog dat bij acute en/of levensbedreigende aandoeningen een ander beleid nodig is dan bij patiënten met chronische multimorbiditeit die redelijk functioneren, of bij patiënten met vroege stadia van gezondheidsproblemen.

\section{Tot slot}

Begrippen als positieve gezondheid, preventie en voorzorg komen met stip binnen op de politieke en beleidsagenda's in binnen- en buitenland. Zorginstituut NL, de NPHF Federatie voor Gezondheid en de Federatie Medisch Specialisten hebben er een mening over. In hun respectievelijke publicaties worden opvallend vergelijkbare analyses en perspectieven neergelegd. Dat stemt positief en duidt op een gelijkgestemde beweging. Dan is het nu tijd voor de bijbehorende gezamenlijke acties, waarbij de inzet is dat de gehele beroepsgroep van artsen de beweging van nazorg naar voorzorg gaat omarmen en uitdragen, wil zij als een van de 'dragers' van de volksgezondheid geloofwaardig en effectief blijven.

\section{Literatuur}

1. RIVM. VTV 2014. Een gezonder Nederland 2014. http:// www.eengezondernederland.nl/Heden_en_verleden/ Ziekten/Chronische_ziekte_en_multimorbiditeit. Geraadpleegd op 24 februari2017.
2. Plochg T. Reconfiguring health professionalism towards addressing multimorbidity. Eurohealth Inc Euro Obs. 2013;19(2):24-7.

3. OECD. Health Workforce Policies in OECD Countries. Right jobs, right skills, right places. Paris: OECD Health Policy Studies; 2016.

4. Orueta JF, Garciá A, lvarez A, et al. Prevalence and costs of multimorbidity by deprivation levels in the Basque country: a population based study using health administrative databases. PLOS ONE. 2014;9(2):e89787.

5. Starfield B. Point: the changing nature of disease: implications for health services. Med Care. 2011;49:971-2.

6. Plochg T. Als je op tijd bent, kom je nooit te laat. Het wenkende perspectief van voorzorg voor de Nederlandse gezondheidszorg. Utrecht: NPHF Federatie voor Gezondheid; 2014. http://www.nphf.nl/standpunt/030/Als-jeop-tijd-bent-kom-je-nooit-te-laat/.

7. Alles is Gezondheid. Voorgangsmonitor pledges. Amersfoort: Alles is Gezondheid; 2016. http://www. allesisgezondheid.nl/monitoring.

8. Santen H van, Maassen H. Interview met minister Schippers. 'Ik zie gedreven professionals, geen weigerachtige dokters' 'NationaalZorgfonds is misplaatstenostalgie'. Med Contact(Bussum). 2016;71(38):1408.

9. Commissie Innovatie Zorgberoepen \& Opleidingen. Naar nieuwe zorg en zorgberoepen: de contouren. Diemen: Zorginstituut Nederland; 2015.

10. CommissieInnovatieZorgberoepen\&Opleidingen. Anders kijken, anders leren, anders doen. Grensoverstijgend leren en opleiden in zorg en welzijn in het digitale tijdperk. Diemen: Zorginstituut Nederland;2016.

11. NPHF. Actieagenda Beroepen \& Opleidingen. Utrecht: NPHF Federatie voor Gezondheid; 2015.

12. Federatie Medisch Specialisten. Medisch Specialist 2025. Utrecht: Federatie Medisch Specialisten;2017. 